\title{
Treatment of Eczema with an Indigenous Drug Manjishtha (Rubia Cordifolia Linn.) - A Preliminary Study
}

\author{
${ }^{1}$ Narendra S. Bhatt, Manasi Deshpande ${ }^{2}$ \\ ${ }^{1}$ Hon. Research Director and Adjunct Professor, Bharati Vidyapeeth University, College of Ayurved, \\ Pune Maharashtra- India \\ ${ }^{2}$ Professor and Head, Department of Dravyaguna Vigan, Bharati Vidyapeeth University, \\ College of Ayurved, Pune Maharashtra- India
}

\begin{abstract}
Eczema, a common skin disease is similar to Vicharchika as described in Ayurved literature. Twenty-one patients of different types of eczema were treated with $35 \%$ ointment of ManjishthaRubiacordifolia,Linn.), made in white petroleum jelly for two weeks. The results of this clinical study showed statistically significant improvement $(p<0.5)$ by Student's ' $t$ ' test with drop in basal severity index of signs and symptoms from $9.86+.51$ (S.E.) $3.72+0.12$ (S.E.) after two weeks of topical treatment. Maximum improvement was observed in exudation, secondary infection and itching. Manjishtha ointment with improvised strength and complimented with oral treatment are proposed.

Keywords:- Eczema, Manjishtha Ointment, Rubia cordifolia,
\end{abstract}

\section{Introduction}

Eczema is considered to be one of the most common skin diseases. Topical corticosteroids are the most widely prescribed medication for dermatological diseases including eczema as they are soefficient in treating inflammatory and epidermal proliferative diseases [1]. Therapeutic response in early acute and sub-acute stages with corticosteroids could be excellent in prompt andadequate treatment is solicited. Occasionally, it will be necessary for patients with extensive disease to be treated with large quantities of the more potent preparations for a short time [2].

However, with large quantities of these potent preparations transient adrenal suppression is likely to occur, especially early in the treatment.Also, evidence of mild suppression of the HPA axis - 'hypothalamis pituitary adrenal axis' is reported in adults when the more potent topical steroids were used, with rapid recovery of the function when intensive treatment ceased [3].

Untreated or partially treated eczema becomes more chronic requiring treatment for a longer period. There possibility of increase in the cutaneous flora of micro-organisms and dermatophytes, during the treatment with a steroid preparation [4]. The cost becomes prohibitive and quantity inadequate as corticosteroid preparations is not economical particular for poor patients of eczema where it is more common.

Description of a skin disease similar to that of eczema is in Ayurvedic classical text as Vicharchika, viz, "Sakandu Pidaka Shyava Bahusrava" meaning skin lesion with hyper pigmentation, vesicles, itching and profuse exudation is termed Vicharchika. [5] [6]

Manjishtha, (Rubia cordifolia Linn.), an indigenous drug is claimed to have astringent, anti inflammatory and antiseptic properties. It is major ingredient of several Ayurvedic formulations like Manjishthadi Kwath, an aqueous decoction, Manjishthadi Churna, a powder and Manjishthadi Malahar, an ointment that are used for various skin diseases [7].

This study was aimed to evaluate the effect of Manjishtha Malahar, an ointment made with powder of Rubia cordifolia, Linn to treat Vicharchika - eczema.

\subsection{Patients}

\section{Materials And Methods}

Patients between the age group of 18-78 years attending out-patient department of an academic hospital in Mumbai and suffering from eczema for the duration of 3 months to 3 years and those fulfilling the criteria for inclusion were selected irrespective of sex, race, caste and religion,

\subsection{Manjishtha Ointment}

Thirty-five percent ointment of the 80 mesh fine powder of the roots of Rubia cordifolia, Linn., prepared with white petroleum jelly was used for the trial. Approximately 15-30 grams of ointment was supplied to the patient depending on the extent of lesion along with instructions to apply it three times a day for a period of two weeks. No other medication, topical or systemic was permitted during the trial. No specific dietetic instructions were given. 


\subsection{Design of study}

This was an open label, single group and non-controlled clinical trial.

\subsection{Period of treatment}

The study was conducted for a period of two weeks in each case.

\subsection{Criteria for assessment}

Carefully observed clinical diagnosis of eczema based on critical signs and symptoms was carried out. Criteria for assessment of results were based onthe score of signs and symptomsbefore and afterthe treatment.Itching, papules, vesicles, exudation, crusting, secondary infection, scaling, lichenification, redness, warmth, edema, burning, hyper-pigmentation these signs and symptoms, usually noticed in eczema were evaluated by carefully observing the skin lesions with a magnifying lens.The severity of signs and symptoms was graded as absent $=0$, mild $=1$, moderate $=2$ and severe $=3$. [8]

Theinvestigators independently observed the patients and in case of disagreement on grading, the less improvement was considered to avoid any bias in favor of the drug.

Overall effect of the treatment with Manjishtha ointment was calculated with reference to percentage improvement in all symptoms. The relief was assessed between $0<24 \%$ as no improvement, $25<49 \%$ as mild, $50<74 \%$ as moderate and $75<100 \%$ as marked improvement.

The sum total of the gradations of signs and symptoms was termed as severity index. The drop in the mean severity index was subjected to a statistical analysis using student's ' $t$ '- test for significance.

\subsection{Observations}

\section{Results}

Out of 21 patients who underwent clinical study there were three drop outs, two had attended first follow-up with positive results but did not continue thereafter.

There were 9 patients with chronic eczematous dermatitis, 5 with contact eczematous dermatitis, 3 eachhad acute eczematous dermatitis and neuro dermatitis and one patient had nummular eczema. Evaluation of thepatients was done basally, on 4th day and at the end ofthe 1st and 2nd week of the trial without placing any leading questions.During follow-up visitssubjective and objectiveamelioration of the lesions was recorded. 12 patients were observed for one more week after the study period and further follow-up was done for a period of 2 months in 4 cases and for 4 months in 3 cases.

Table 1: Effect of the drug on different signs and symptoms- percentage improvement

\begin{tabular}{|c|c|c|c|c|c|c|}
\hline \multirow[t]{2}{*}{ Sign or symptom } & \multirow{2}{*}{$\begin{array}{l}\text { Total No. } \\
\text { of patient }\end{array}$} & \multirow[t]{2}{*}{ No effect } & \multicolumn{4}{|c|}{ Percentage improvement with no. of Patients } \\
\hline & & & $0-24 \%$ & $25-49 \%$ & $50-74 \%$ & $75-100 \%$ \\
\hline Itching & 18 & 1 & - & 1 & 9 & 7 \\
\hline Papules & 8 & 1 & - & 1 & 2 & 4 \\
\hline Vesicles & 12 & 3 & - & - & 1 & 8 \\
\hline Exudation & 13 & 1 & - & 1 & 1 & 10 \\
\hline crusting & 9 & - & - & - & 2 & 7 \\
\hline Sec. infection & 6 & 1 & - & - & - & 5 \\
\hline Scaling & 14 & 4 & - & 4 & - & 5 \\
\hline Lichenification & 15 & 5 & 2 & 1 & 4 & 3 \\
\hline Redness & 7 & - & - & - & 2 & 5 \\
\hline Warmth & 5 & - & - & - & 1 & 4 \\
\hline Oedema & 6 & - & - & - & 1 & 5 \\
\hline Burning & 8 & - & - & - & 3 & 5 \\
\hline Hyperpigmentation & 15 & 7 & - & 3 & 5 & - \\
\hline
\end{tabular}

Table 2: Effect of the drug with regard to signs and symptoms- severity score

\begin{tabular}{|l|l|l|l|}
\hline Sign or symptom & Total No. of patient & \multicolumn{2}{|l|}{ Mean severity score } \\
\hline Itching & 18 & 1.9 & 0.66 \\
\hline Papules & 08 & 1.2 & 0.39 \\
\hline Vesicles & 12 & 1.0 & 0.38 \\
\hline Exudation & 14 & 1.46 & 0.21 \\
\hline crusting & 09 & 1.19 & 0.88 \\
\hline Sec. infection & 07 & 1.4 & 0.25 \\
\hline
\end{tabular}




\begin{tabular}{|l|l|l|l|}
\hline Scaling & 14 & 1.32 & 0.58 \\
\hline Lichenification & 17 & 1.12 & 0.92 \\
\hline Redness & 07 & 1.0 & 0.23 \\
\hline Warmth & 05 & 0.85 & 0.12 \\
\hline Oedema & 06 & 1.34 & 0.24 \\
\hline Burning & 07 & 1.24 & 0.25 \\
\hline Hyperpigmentation & 15 & 1.2 & 1.0 \\
\hline
\end{tabular}

The maximum improvement was observed in exudation, secondary infection and itching. The drop in mean severity score of exudation was from 1.46 to .21 (14 patients). In itching it was from 1.9 to 0.66 (18 patients) whereas in secondary infection it was from 1.4 to .25 (7 patients). The minimum improvement was in lichenification and hyper pigmentation. The drop in mean severity score of lichenification was from 1.12 to 0.92 (17 patients) while that ofhyper pigmentation from 1.2 to 1.0 (15 patients).

The mean basal Severity scores of 18 patients before treatment and at the end of two week trial was $9.86+.51$ S.E., which after treatment dropped to $3.72+.12$ S.E. The difference is statistically significant $(\mathrm{p}$ $<0.05$ by $^{6} \mathrm{t}$ ' test).

Table 3: Percentage improvement in various types of eczema

\begin{tabular}{|l|l|l|l|l|l|l|}
\hline Type of Eczema & \multirow{2}{*}{ No. of patients } & \multicolumn{3}{|l|}{ Improvement in percentage } & Side effects \\
\cline { 3 - 8 } & & $\mathbf{0 - 2 5 \%}$ & $\mathbf{2 6 - 5 0 \%}$ & $\mathbf{5 1 - 7 5 \%}$ & $\mathbf{7 5 - 1 0 0 \%}$ & \\
\hline Chr. Ecz.Derm. & $\mathbf{7}$ & - & $\mathbf{1}$ & $\mathbf{3}$ & $\mathbf{2}$ & $\mathbf{1}$ \\
\hline Cont.Ecz.Derm & $\mathbf{5}$ & - & - & $\mathbf{1}$ & $\mathbf{4}$ & - \\
\hline Acute Ecz. Derm & $\mathbf{2}$ & - & - & $\mathbf{1}$ & $\mathbf{1}$ & - \\
\hline Neurodermatitis & $\mathbf{3}$ & - & $\mathbf{1}$ & $\mathbf{1}$ & $\mathbf{1}$ & - \\
\hline Nummular Ecz & $\mathbf{1}$ & - & - & - & $\mathbf{1}$ & - \\
\hline Total & $\mathbf{1 8}$ & - & $\mathbf{2}$ & $\mathbf{6}$ & $\mathbf{9}$ & $\mathbf{1}$ \\
\hline
\end{tabular}

Seventeen patients showed satisfactory improvement, while 1 patient had allergic manifestations. The maximum drop in severity index in a patient was from 6.5 to 0.5 (92.3\%), the minimum being 9.5 to 6.0 (36.84). The improvement in terms of percentage was $62.06 \%$ being the average improvement. More than $50 \%$ improvement was observed in 4 days in 4 patients.

\subsection{Adverse effect}

One female patient showed notable improvement in the affected lesions, however, allergic manifestations in the form of exudation and vesicles on both the fore arms and oedema and urticarial rashes on face were observed. This patient was knownto be allergic to most of the available dermatological productsas learnt from her previous history. This patient when treated with regular Ayurvedic treatment to which she responded well within a week's time.

Adverse effects of any other kind were not observed in the remaining patients.

\subsection{Follow up and non-recurrence}

Twelve patients who were treated for one more week showed a furtherimprovement by $10 \%$, thus bringing total mean improvement in these patients to $80.4 \%$. The mean severity index of these patientsdropped from 10.00 to 1.9 in 3 weeks.Papules, vesicles, exudation, secondary infection and warm, almost disappeared, thereby severity score approaching the zero grade in all cases. Crusting, oedema and burning responded in a similar fashion, except for one patient in each case. Other symptoms showed gradual improvement. Notable improvement in hyper pigmentation was observed during this additional period which was not observed during earlier period.

No recurrence was observed in 7 patients, of whom 4 were observed for 2 months and 3 patients for 4 months.

\section{Discussion}

Present day treatment of eczema is with corticosteroids, eitherused topically or systemically. Topical steroids are not veryeconomical and when used for long time have adverse effects or at times cause relapse on withdrawal. Newer and potent corticosteroids like hydrocortisone, train cinolone, beta methasone and others are claimed to have less side effectscompared to earlier.

Ayurvedic classics have described use of Manjishtha, Rubia cordifolia in different forms for treatment of diseases similar to eczema. 
The results of thispreliminary study are encouraging. The maximum effect observed in exudation suggests anti-exudatory activity. The marked improvement in secondary infection confirms the reports as per Gam and Wang (1949) [9] and Kurup (1956) [10]. Alsonotable improvement in itching suggests the anti-pruritic effect of the plant. The results in lichenification and hyper pigmentation at the end of two week trial are poor; however, in 12 patients where the treatment was extended for one week more there was significant improvement in lichenification as well. This effect is justified as these signs indicate the chronicity of the lesion, and the aim of the trial was to study the acute effect of the drug.

To exclude the physicians 'halo effect' and to evaluate theefficacy controlled trials are necessary. Only strength of ointment $(35 \%)$ has been used in this trial. Different percentage of ointment may change the therapeutic response.Topical treatment combined with oral treatment and only oral treatment of the same drug requires to be studied.

\section{Conclusion}

This preliminary clinical study confirms use of ointment made with Manjishtha for effective treatment of Vicharchika - eczema having observed significant improvement in various symptoms of Eczema. Further studies are recommended with larger sample size and higher strength of ointment with a standard control drug in order to validate its efficacy to obtain a safe and economic alternative in management Eczema.

\section{Acknowledgements}

We acknowledge thanks to Dean, M. A. Podar Hospital and to M/s. Indo-Continental Pharmaceutical Agency for financial help to this project.

\section{References}

[1]. Michael Lee and Robin Marks, The role of corticosteroids in dermatology, Australian prescriber, volume 21, number 1, January 1998.

[2]. Sparks, C.G, Measuring adrenal function inoutpatients usingtopical corticosteroids. British Journal of Dermatology (94), Supplement $12,77,1976$

[3]. Munro, D.D, The effect of percutaneous absorbed steroids on hypothalamic- pituitary - adrenal functionsafter intensive use in patients, British Journal of Dermatology (94), Supplement s12, 67, 1976

[4]. Savin, J.A, Topical steroids and bacterial infection, British Journal ofDermatology, (94), Supplement 12,125, 1976

[5]. Charak: Charak Samhita - Chikitsasthan, $7 / 27$, , Vidyotini Hindi Commentary edited by Vaidya Kashinath Shashtri and Gorakhanath Chaturvedi,Chaukhamba Orientalia, Varanasi, 1984, pp 252-253

[6]. Vagbhatta: AshtangHridaya,Nidansthan, $14 / 17$, Translated by Vijayashankar Munashi, SastuSahityaVardhak Karyalaya,3rd Edition,1972, pp 336

[7]. Wealth of India: Raw Materials, Vol. IX (Rh-So), CSIR, New Delhi,1972

[8]. E.J. Glazenburg, A. Wolkerstorfer and F.B. De Waard-van der Spek, Practical issues on Interpretation of scoring atopic dermatitis: the

[9]. SCORAD index, objective SCORAD and the three-item severity score, A.P. Oranje, British Journal of Dermatology Volume 157, Issue 4, pages 645-648, October 2007

[10]. Gam, S. and Wang, G.P, Antibacterial drugs in Chinese drugs. Science, 110, 11, 1949

[11]. Kurup P.A. (1956) : Studies on plant antibiotics; Screening of some Indian Medicinal plants, Journal of Scientificand Industrial Research (50), 153, 